\title{
Mediação da informação e estudos de usuários: interrelações ${ }^{1}$
}

\author{
Information mediation and user studies: interrelations
}

Adriana Bogliolo Sirihal Duarte

Doutora em Ciência da Informação pela Universidade Federal de Minas Gerais - UFMG

Professora adjunta da Escola de Ciência da Informação da UFMG

E-mail: bogliolo@eci.ufmg.br

\begin{abstract}
Resumo
A partir da experiência na condução da disciplina Usuários da Informação e de ações de extensão e de pesquisa desenvolvidas junto a usuários de uma biblioteca itinerante, objetiva-se a reflexão sobre o relacionamento entre os estudos sistemáticos de usuários da informação e o papel de mediação informacional. A fundamentação teórica baseia-se em definições de estudos de usuários correntes na literatura da Ciência da Informação bem como em autores que discutem o conceito de mediação. Descrevem-se, sucintamente, pesquisas (estudos de usuário) realizadas em situações que privilegiam a função de mediação. Três estudos de usuários são mencionados: dois estudos qualitativos, em que entrevistas foram utilizadas como método de coleta de dados, para propiciar o desenvolvimento de ações de mediação; e um estudo quantitativo, que visou avaliar os resultados obtidos por uma ação de mediação já implementada. Conclui-se que a mediação pode ser facilitada pela prática de se realizar sistematicamente estudos de usuários bem como pela adoção de alguns métodos e técnicas dos estudos de usuários no cotidiano do trabalho do mediador. E ainda que, embora o trabalho do mediador esteja mudando devido à mudança de suporte da informação (informação em suporte eletrônico), sua função de mediação permanece cada vez mais necessária e deve ser cada vez mais privilegiada na formação do profissional.
\end{abstract}

Palavras-chave: Mediação. Estudos de Usuários. Comportamento Informacional.

\begin{abstract}
Based on the experience of conducting the Information Users discipline in graduate courses and on extension and research activities developed with the users of a mobile library, the goal is to reflect on the relationship between the systematic study of information users and the role of mediation. The theoretical framework is based on the definitions of users and information behavior currently used in Information Science literature as well as on authors who discuss the concept of mediation. The article briefly describes surveys (user studies) performed in situations that emphasize the role of mediation. Three user studies are mentioned: two qualitative studies, in which interviews were used as data collection method, aiming at the development of mediation actions; and a quantitative study, which aims to evaluate the results of a mediation action already implemented. The study concludes that mediation can be facilitated by the practice of conducting systematic user studies as well as by the adoption of some methods and techniques of user studies in the mediator's daily work. And although the mediator's work is changing due to changes in information support (information in electronic media), its function of mediation remains increasingly necessary and should be more favored in the educational training of professionals.
\end{abstract}

Keywords: Mediation. User studies. Information behavior.

\footnotetext{
${ }^{1}$ Artigo apresentado em sua versão original no XII Encontro Nacional de Pesquisa em Ciência da Informação, 2011.
}

InCID: R. Ci. Inf. e Doc., Ribeirão Preto, v. 3, n.1, p. 70-86, jan./jun. 2012. 


\section{Introdução}

Há seis anos venho ministrando a disciplina Usuários da Informação. Em minha primeira aula, em qualquer turma, sempre me sinto na obrigação de convencer os alunos da importância de se estudar o usuário da informação em seus cursos. Vale observar que a IES em que atuo oferece essa mesma disciplina para os cursos de graduação em Biblioteconomia, Arquivologia, Museologia (os três locados na Escola de Ciência da Informação) e Sistemas de Informação (curso oferecido pelo Departamento de Ciência da Computação), além de oferecê-la em nível de pós-graduação para cursos de especialização e para o mestrado e doutorado em Ciência da Informação. Até hoje venho me apoiando, com sucesso, no trabalho desenvolvido por Odília Clark Peres Rabello, quando em 1980 defendeu sua dissertação de mestrado em Administração de Bibliotecas na então Escola de Biblioteconomia da UFMG (RABELLO, 1980; RABELLO, 1981). Suas considerações influenciaram sobremaneira na inclusão da disciplina Usuários da Informação como obrigatória no currículo mínimo de graduação em Biblioteconomia:

Embora o usuário como disciplina e tema de pesquisa fosse uma realidade nos cursos de pós-graduação, nos eventos e nas publicações periódicas e já se firmasse como área de conhecimento nos anos 70, como disciplina no ensino de graduação só entraria no currículo a partir da reformulação curricular de 1982 (NASCIMENTO, 2011, p. 56-57).

Rabello nos leva por um percurso em que, a partir da definição dos conceitos de biblioteca e de biblioteconomia, demonstra a importância do usuário como campo de estudo na biblioteconomia. Ela parte das definições de Shera $^{2}$ e de Nitecki ${ }^{3}$ :

Para Shera, a biblioteconomia é uma trindade formada de aquisição, organização e disseminação. (...) Os conceitos básicos da disciplina são indivíduos, registros gráficos e organização técnica. Esses conceitos podem ser representados sob a forma de um triângulo, cujos lados seriam constituídos pelos indivíduos e registros gráficos e a base pela biblioteca e suas formas de tornar os registros acessíveis aos leitores (...) Já Nitecki define a biblioteconomia a partir da hipótese que relaciona os termos livros (b), usuário (u), conhecimento (k). (...) Para ele, a biblioteconomia tem como finalidade permitir, de diferentes formas, que os leitores tenham acesso ao conhecimento disponível através de bibliotecas (RABELLO, 1980, p.20).

\footnotetext{
2 SHERA, Jessé Hank. The foundations of education for librarianship. New York, Becker and Hayes, 1972. (citado por RABELLO, 1980).

${ }^{3}$ NITECKI, Joseph. Reflection on the nature and limito f library science. The Journal of Library History. Tallahasse, 3(2): 103-19, pr. 1968 (citado por RABELLO, 1980).
} 
Figura 1: Composição da Biblioteconomia

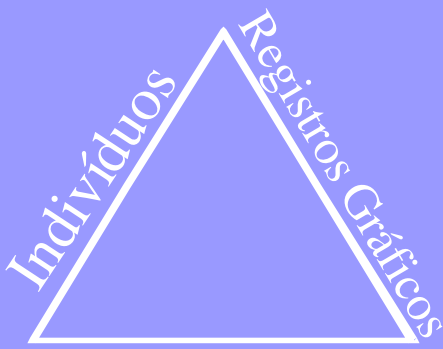

Biblioteca

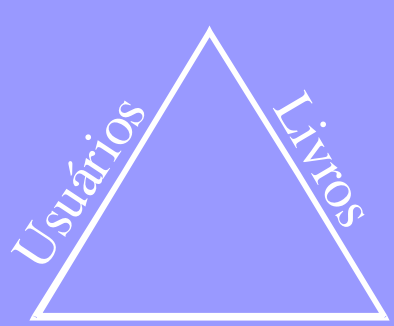

Conhecimento

FONTE: Elaborada pela autora a partir de RABELLO, 1980, p. 20.

Observa-se a clara convergência na definição dos autores. Em resumo, o estudo da biblioteconomia perpassa pelo estudo dos registros (documentos, registros gráficos, livros, acervo, fontes de informação ou qualquer outra denominação) - e para estudá-los os cursos de graduação em biblioteconomia têm disciplinas próprias; e das formas de organização de tais registros, a fim de constituir uma biblioteca ("o local onde uma coleção organizada e constituída de acordo com a demanda e necessidade dos usuários efetivos e potenciais a que se destina [...], está à disposição dos interessados, para suprir suas necessidades informativas, educacionais ou recreativas" (TARGINO, 1984, p. 59) - e para estudar essas formas de organização há tantas outras disciplinas curriculares.

No entanto, estamos falando de uma tríade, que seria ainda melhor representada pela imagem de um tripé, do que pela imagem de um triângulo. Um tripé só se sustenta se apoiado nos três vértices - imagine-se a corriqueira imagem de um banquinho, um tamborete de três pés. Se um de seus pés for removido, o banquinho literalmente cai. Daí a importância do terceiro vértice, donde se conclui que para a formação de um profissional bibliotecário não basta estudar os registros e suas formas de organização. Há que se estudar, com igual peso e importância, o usuário, o indivíduo para quem tal informação deverá ser disponibilizada. Rabello conclui: “A finalidade da biblioteca é a transferência de informação ao usuário e as três áreas básicas de conhecimento da biblioteconomia são: materiais que vão ser comunicados; métodos usados para sua organização; usuários - os receptores da informação” (RABELLO, 1980, p. 21).

Tem sido fácil demonstrar para meus alunos como a trindade que compõe a biblioteconomia facilmente se aplica à arquivologia, museologia e sistemas de informação. Em todas essas áreas existem os três campos do conhecimento: os registros (documentos, objetos museais, bancos de dados), suas formas de organização (típicas de cada uma das áreas) e, sem dúvida, o usuário.

InCID: R. Ci. Inf. e Doc., Ribeirão Preto, v. 3, n.1, p. 70-86, jan./jun. 2012. 
Isso fica ainda mais explícito no paradigma pós-custodial destes serviços de informação: se em determinado momento histórico o paradigma das bibliotecas, arquivos e museus foi custodial, de guarda e para preservar a memória, hoje o paradigma é completamente outro e está totalmente centrado no usuário: estas instituições servem para promover o acesso à informação pelos indivíduos (SILVA, 2010).

O próximo passo de meu percurso é, então, demonstrar que se o usuário precisa ser levado em consideração, ele deve ser estudado de modo sistemático. Um bom profissional da informação deve conhecer o usuário de sua instituição não apenas através das impressões do contato cotidiano, mas a partir de estudos sistemáticos e cientificamente fundamentados, se quiser realmente oferecer um serviço centrado no usuário:

Se os arquivistas desejam compreender o mecanismo das práticas arquivísticas e as razões dos princípios e teorias, devemos dirigir nossa atenção dos acervos físicos ao uso da documentação [...] devemos começar a aprender de maneira sistemática e não por simples impressões como fazemos agora quem são nossos usuários [...] temos de pensar a administração de arquivos como uma administração centrada no cliente e não nos materiais. (DOWLE, $1992^{4}$ citado por JARDIM; FONSECA, 2004).

É a partir de então que apresento definições clássicas de estudos de usuários e começo a discutir procedimentos metodológicos, métodos e instrumentos de coletas de dados para a efetivação de estudos de usuários. Ressalto que embora todo indivíduo seja considerado usuário de informação, a terminologia "usuário" relaciona-se, tradicionalmente, a um sistema de informação. Os usuários potenciais são aqueles que necessitam de informação, independentemente de que isso se traduza ou não na consulta a uma fonte de informação, na solicitação de informação a outro indivíduo ou à demanda a um sistema de informação. Do ponto de vista de um sistema de informação, usuários potenciais são aqueles para os quais o sistema foi organizado. Isso significa dizer que a coleção e os serviços disponibilizados estão constituídos em função do atendimento de suas possíveis necessidades e demandas. Qualquer usuário potencial pode, portanto, vir a realizar uma demanda ao sistema de informação, e isso depende fundamentalmente de seu próprio reconhecimento de que possui tal necessidade e, adicionalmente, de sua expectativa de ver satisfeita a necessidade, isto é, da antecipação que faz de seu grau de satisfação com as respostas que encontrará. Uma vez que tenha realizado uma demanda, este indivíduo passa a ser denominado usuário efetivo do sistema de informação em questão (TERUEL, 2005, p. 69). Considerada a interrelação entre o usuário e o sistema de

\footnotetext{
${ }^{4}$ DOWLE, Lawrence. Agenda de investigación sobre la disponibilidade y uso de los archivos. Foro Archivistico, México, n. 4, jul./dec. 1992 (citado por JARDIM; FONSECA, 2004).
} 
informação, são reconhecidas, no Brasil, entre outras, as definições de Figueiredo e de Dias e Pires para estudos de usuários. Elas concordam em afirmar que estudos de usuários são investigações:

1. “(...) que se fazem para saber o que os indivíduos precisam em matéria de informação, ou então, para saber se as necessidades de informação por parte dos usuários de uma biblioteca ou de um centro de informação estão sendo satisfeitas de maneira adequada" (FIGUEIREDO, 1994, p. 7).

2. “(...) que objetivam identificar e caracterizar os interesses, as necessidades e os hábitos de uso de informação de usuários reais e/ou potenciais de um sistema de informação" (DIAS; PIRES, 2004, p. 11).

Onde fica a mediação nessa história toda? A primeira constatação é a de que o profissional que atua explicitamente como mediador deveria, sempre que possível, fazer estudos sistematizados de seus usuários. E que, em seu cotidiano, deve aprender a fazer "micro estudos", pequenas análises individuais de cada usuário que atende ou com que se relaciona. Se for capaz de introjetar essa capacidade de observar com rigor e analisar com discernimento as necessidades trazidas pelo usuário, será capaz de oferecer, sem dúvida, um serviço diferenciado.

Em pesquisa acerca do processo de mediação da informação em bibliotecas universitárias, Novelli, Hoffmann e Gracioso (2011, p. 7) concluem que "um componente essencial para facilitar a mediação da informação é conhecer os usuários, os seus estilos de aprendizagem, suas atitudes e que as suas abordagens devem diferir de acordo com suas principais características".

\section{Estabelecimento do relacionamento entre mediação da informação e estudos de usuários}

Silva (2010) busca conceituações de mediação em inúmeros dicionários e enciclopédias e apresenta desde o conceito jurídico da mediação (procedimento para resolução de controvérsias, quando uma terceira pessoa - o mediador - assiste ou conduz duas ou mais partes negociantes visando por fim a conflitos) até o conceito de mediação cultural (atividades de aproximação entre indivíduos e obras de cultura). O mediador cultural nesse caso - função muitas vezes atribuída aos profissionais de biblioteca e de museu - assume o papel de animador cultural (promotor de ações culturais).

InCID: R. Ci. Inf. e Doc., Ribeirão Preto, v. 3, n.1, p. 70-86, jan./jun. 2012. 
Para Davallon (2007, p. 2) a mediação cultural

(...) pode ser definida, sem dúvida, a nível funcional: visa fazer aceder um público a obras (ou saberes) e a sua ação consiste em construir uma interface entre esses dois universos estranhos um ao outro (o do público e o, digamos, do objeto cultural) com o fim precisamente de permitir uma apropriação do segundo pelo primeiro.

Mais adiante o autor propõe: "notaremos que a mediação dos saberes constitui um domínio quase específico, que reenvia, por um lado à mediação da informação e, por outro, aos aspectos sociais ou semióticos da comunicação" (ibidem, p. 8).

Para Smit (2003, p. 7) a mediação da informação define-se como "a comunicação de informações objetivando uma efetiva transferência da informação, em função das necessidades informacionais dos usuários" e para Almeida Júnior (2009, p. 92) como "toda ação de interferência - realizada pelo profissional da informação -, direta ou indireta; consciente ou inconsciente; singular ou plural; individual ou coletiva; que propicia a apropriação de informação que satisfaça, plena ou parcialmente, uma necessidade informacional”.

Em consonância com Almeida Junior (2009), concordamos que

[...] a mediação está presente em todos os fazeres do profissional da informação. Em algumas ações, no entanto, a mediação está presente de forma implícita, muito embora dirigindo e norteando todas as atividades ali desenvolvidas. $\mathrm{O}$ armazenamento de informações é alimentado a partir de interesses e demandas dos usuários. A política de seleção, amplamente discutida no desenvolvimento de coleções, tem o usuário final como base de sustentação. O mesmo se dá com os trabalhos de processamento das informações: têm suas ações voltadas para a recuperação de informações que atendam e satisfaçam necessidades dos usuários.

É inconcebível a ideia de trabalhos não voltados para o atendimento de necessidades informacionais. Tais trabalhos seriam vazios e desprovidos de objetivos.

Esse, entre outros fatores, tornou possível (e quase inevitável) a distinção da mediação entre implícita e explícita. A primeira, a mediação implícita, ocorre nos espaços dos equipamentos informacionais em que as ações são desenvolvidas sem a presença física e imediata dos usuários. Nesses espaços, como já observado, estão a seleção, o armazenamento e o processamento da informação. A mediação explícita, por seu lado, ocorre nos espaços em que a presença do usuário é inevitável, é condição sine qua non para sua existência, mesmo que tal presença não seja física, como, por exemplo, nos acessos a distância em que não é solicitada a interferência concreta e presencial do profissional da informação (ALMEIDA JÚNIOR, 2009, p. 92-93).

$\mathrm{O}$ senso comum, quando se fala em mediação da informação, nos evoca à mediação explícita, efetuada mais frequentemente pelo bibliotecário ou pelo arquivista de referência:

Grogan (2001, p.7-34) afirma que o serviço de referência proporciona assistência individual e direta a usuários que buscam informações em um 
determinado acervo. Tais serviços beneficiam tanto os usuários como a instituição mantenedora. Os usuários são beneficiados por encontrarem as informações de que necessitam e a instituição por demonstrar-se eficaz em promover um fluxo eficiente de informação que facilita a busca e acesso da informação pelo usuário (GAMA; FERNEDA, 2010, p. 155).

Portanto, por trás do conceito de mediação informacional está a satisfação das necessidades informacionais dos indivíduos. Como os estudos de usuários visam conhecer as necessidades informacionais dos indivíduos, eles se configuram em excelente instrumento de trabalho para os mediadores de informação.

Fernanda Ribeiro (2009, p. 31) categoriza os estudos de usuários em tipos distintos:

os estudos de necessidades e usos, que investigam o comportamento dos utilizadores no processo de pesquisa de informação; os estudos de satisfação, que pretendem determinar até que ponto a informação obtida, na sequência de uma pesquisa, satisfaz a necessidade de informação que ocasionou a mesma pesquisa, ou seja, pretendem saber se quem procura encontra aquilo que procura; e os estudos de impacto ou benefício, que procuram avaliar os contributos da informação obtida para o trabalho dos utilizadores que efetuaram a pesquisa.

Para a autora, "de todos esses tipos de estudos, os que mais diretamente interessam, na perspectiva da mediação, são os estudos de necessidades e usos" (RIBEIRO, 2009, p.31). É preciso compreender as necessidades do usuário para melhor atendê-las. Interessam, portanto, os estudos de usuários na abordagem centrada no próprio usuário (em oposição à abordagem centrada no sistema). Tradicionalmente, os estudos de usuários foram categorizados naqueles centrados no sistema ou na biblioteca e nos estudos centrados nos usuários. Os primeiros, em que o usuário é consultado para dar subsídios para a oferta de um melhor serviço, se aproximam bem dos estudos de satisfação, pois visam garantir o cumprimento da expectativa do usuário em relação ao sistema, isto é, sua satisfação com os serviços oferecidos. Já os estudos de usuários centrados nos usuários visam avaliar como um indivíduo ou um grupo de indivíduos se comporta para obter as informações de que necessita.

Outra subdivisão comum na literatura classifica os estudos em tradicionais ou alternativos. Ao passo que os tradicionais compreendem a informação como objetiva, independente do usuário que a recebe e a interpreta, e atribuem ao usuário o papel de buscador dessa informação externa a ele; os estudos alternativos percebem a informação como subjetiva, seu significado é atribuído pelo usuário que com ela interage (informação = conteúdo + interpretação) e o papel do usuário não é apenas o de buscar a informação mas também o de a ela atribuir sentido. O conceito central dessa abordagem não é, portanto, a informação, e sim o 
indivíduo: trata-se de uma teoria do indivíduo como o buscador e interpretador de informação na qual o estudo dos processos informacionais significa analisar os processos mentais e cognitivos do indivíduo. O ser humano é visto como possuidor de um estado de conhecimento que é afetado e transformado quando ele percebe, recebe e internaliza nova informação. A fragilidade deste ponto de vista reside no fato de que "ele presta pouca atenção aos aspectos sociais dos processos informacionais, seja em termos do contexto sócio-cultural dos usuários seja no contexto sócio-cultural dos sistemas de informação" (TALJA, 1996, p. 67). É preciso ter-se em conta que as estruturas de conhecimento são construídas socialmente e culturalmente.

Assim, recentemente, os estudos buscam, além de tudo, ser mais abrangentes. Não se restringem à interação do indivíduo com o sistema de informação, mas buscam compreender o contexto que gerou a necessidade de informação, bem como os usos dados à informação uma vez assimilada, na solução dos problemas ou situações que implicaram na necessidade de informação, ou seja, avaliam não somente o comportamento de busca da informação, mas todo o comportamento informacional do indivíduo.

\section{Figura 2: Abrangência dos Estudos de Usuários}

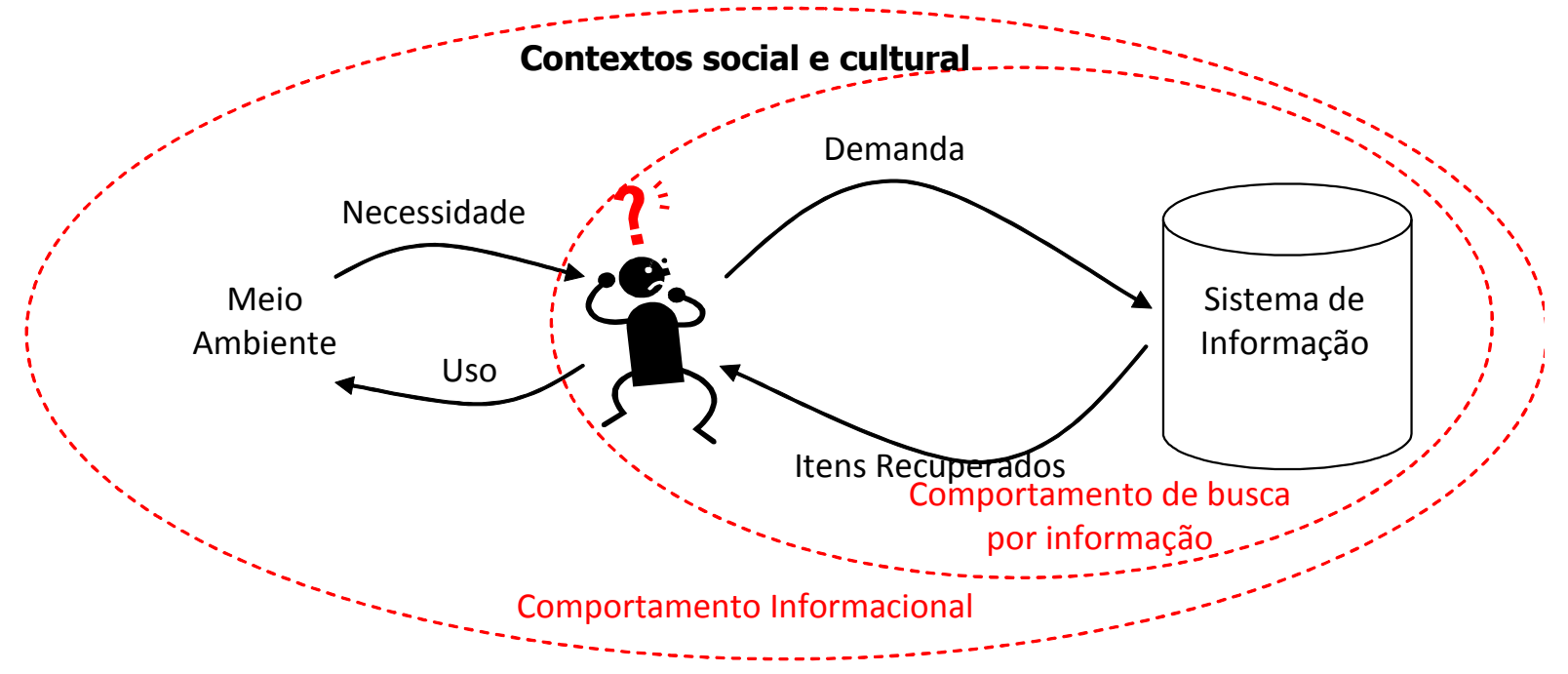

Fonte: elaborada pela autora

Wilson (2000, p. 49) define comportamento informacional como a totalidade do comportamento humano em relação a fontes e canais de informação, incluindo tanto a busca de informação ativa (o sujeito empreende uma busca proposital para suprir uma necessidade informacional) quanto passiva (o encontro acidental com a informação que supra a necessidade do sujeito), e também o uso da informação. $\mathrm{O}$ autor diferencia este conceito mais amplo de 
outros mais específicos que o compõem, a que denomina comportamento de busca por informação (information seeking behavior), comportamento de busca em um sistema de informação (information searching behavior) e comportamento no uso da informação (information use behavior).

O comportamento de busca por informação refere-se à busca intencional por informação como consequência da necessidade de satisfazer algum objetivo. Durante esse processo de busca o indivíduo pode vir a interagir tanto com sistemas de informação manuais (por exemplo, jornais ou bibliotecas) quanto computadorizados (por exemplo, sistemas de informação automatizados ou a world wide web).

À interação do indivíduo com algum desses sistemas é que se denomina comportamento de busca em um sistema de informação. Trata-se, segundo Wilson, de um micro-nível de comportamento empregado no instante da interação do indivíduo com o sistema de informação selecionado. Ele apresenta exemplos de atividades que caracterizam essa interação do indivíduo com um sistema de informação computadorizado, tais como o uso do mouse, a seleção de determinados links, a escolha de uma expressão de busca adotando ou não operadores booleanos e mesmo as operações mentais que permitem, por exemplo, julgar a relevância de uma informação recuperada.

Finalmente, o comportamento no uso da informação consiste nas ações físicas e mentais envolvidas na incorporação da informação encontrada ao repertório de conhecimento do sujeito.

Ribeiro (2009, p. 32) ainda lembra que a preocupação com as necessidades individuais dos usuários e seu comportamento de busca por informação promoveu o desenvolvimento de novos modelos interpretativos dos comportamentos informacionais, já que os métodos tradicionais de investigação na área dos estudos de usuários não eram mais adequados. Entre os novos modelos emergentes, um que ganhou notoriedade foi o Sense Making Approach de Brenda Dervin.

Proponho uma provocação - a análise paralela do modelo de Dervin e do processo do serviço de referência descrito por Grogan (2001, p. 50-54).

Dervin propõe a metáfora de um caminhante que, em determinado momento, se depara com uma situação de parada (DERVIN; NILAN, 1986). Essa situação é representada por uma lacuna, ou um buraco no meio do caminho (Drummond, mais poeticamente, encontra uma pedra no meio de seu caminho) que representa uma lacuna ou necessidade informacional. Cada 
indivíduo cria, então, estratégias para transpor esse obstáculo. Tais estratégias representariam os comportamentos de busca de informação. Quando uma estratégia resulta na obtenção da informação de que se necessitava, o indivíduo "constrói uma ponte" e atravessa a lacuna, retomando sua caminhada.

Como método de coleta de dados para estudos de usuários que utilizam essa metáfora, Dervin sugere a aplicação de entrevistas da linha do tempo: cada participante deve reconstruir uma situação em termos dos acontecimentos e passos que formaram a linha do tempo da situação. Para tal, sugere que lhe sejam feitas perguntas para:

1. Compreensão da situação (Que aspecto desta situação o concerne? Por onde você gostaria de começar? O que o trouxe à este ponto? No que você está trabalhando?);

2. Compreensão das lacunas ( $\mathrm{O}$ que parece estar faltando? O que você está tentando entender? O que você gostaria de saber a respeito disso? Você está procurando o sentido de que? Que confusões você está tentando superar?);

3. Compreensão dos auxiliadores (O que o ajudaria? O que você está tentando fazer? Você se vê indo para que direção? Como você planeja usar isso?).

4. Grogan apresenta o processo do serviço de referência em oito etapas consecutivas, a saber:

1. O problema: o problema pode ser compreendido com uma determinada circunstância que atrai a atenção do usuário para o acervo. Pode ser gerado por uma fonte interna, de origem psicológica ou cognitiva, ou de uma fonte externa, contexto social ou situacional.

2. A necessidade de informação: para se lidar com um problema o usuário sente a necessidade de obter informações. A necessidade poderá ser meramente vaga ou mesmo uma curiosidade que motivará o indivíduo a obter uma resposta.

3. A questão inicial: $\mathrm{O}$ usuário formula uma pergunta e a direciona ao profissional da informação.

4. A questão negociada: uma vez formulada a questão inicial inicia-se o processo de referência. A questão inicial poderá exigir maiores esclarecimentos ou ajustes para se certificar qual seria a necessidade de informação subjacente. A questão é então comparada com a maneira como as informações estão registradas no acervo. A comparação permite a reformulação da questão em conformidade com a terminologia e a estrutura das informações a serem consultadas.

5. A estratégia de busca: decide-se como o acervo de informações será consultado e quais de suas partes serão consultadas e em que ordem.

6. O processo de busca: o profissional executa a busca no acervo.

7. A resposta: uma vez encontrada uma resposta, o profissional a apresenta ao usuário para verificar se esta atende a necessidade informacional do usuário.

8. A solução: tendo a resposta atendido às expectativas do usuário o processo dá-se por finalizado (GAMA; FERNEDA, 2010, p. 155-156). 
A minha provocação está na observação de que as etapas 1 a 4 do processo do serviço de referência corresponderiam ao sense making de Dervin. A compreensão do problema e a necessidade de informação acontecem quando o indivíduo se depara com a situação de parada e tenta compreender a situação e a(s) lacuna(s). A questão inicial - postulação de demanda ao sistema de informação - é a efetivação de uma estratégia. No entanto, a etapa 4, de negociação da questão, é o que no início do texto chamei de "micro estudo" de usuário. É o instante no qual o profissional da informação precisa compreender as reais necessidades de seu usuário, a fim de buscar supri-las. Note-se que são inúmeras as vezes que um usuário chega a um serviço de informação sem ter conseguido, por si só, realizar as etapas 1 a 3, isto é, converter o problema em uma questão informacional. Muitos dos usuários externam não suas necessidades, mas sim seus problemas e situações. O profissional de referência deve, portanto, guiá-los a fim de que se tornem capazes de abstrair seus problemas, relacioná-los com lacunas informacionais, associálos a perguntas e partir para o efetivo processo de busca.

A proposição adjacente é: a mediação desse profissional, auxiliando o usuário durante essas 4 primeiras etapas, pode ser facilitada pela adoção de perguntas como as da entrevista na linha do tempo, proposta por Brenda Dervin? O profissional de referência não estaria, portanto, a cada atendimento, realizando um "micro estudo" de usuário? E, portanto, quanto mais familiarizado esse profissional estiver com metodologias de estudos de usuários e com técnicas de coletas de dados, melhor ele vai ser capaz de cumprir essas etapas?

\section{Análises de casos}

Para exemplificar um caso de mediação explícita, em que o bibliotecário ora assume o papel do serviço de referência, ora assume o papel de mediador cultural, trago resultados de ações de extensão e de pesquisa realizadas no Programa Carro-Biblioteca: Frente de Leitura da UFMG. Esse programa de extensão foi implantado pelo Centro de Extensão da Escola de Ciência da Informação da UFMG em 1973. Desde então, leva o acesso ao livro e à informação a comunidades carentes da Grande BH. Atualmente isto é feito através de um ônibus modificado para abrigar uma biblioteca itinerante e um telecentro móvel. O ônibus visita, a cada dia da semana, um bairro, e atende a usuários da região promovendo a consulta e o empréstimo do acervo, oficinas de inclusão digital, atividades variadas como contação de histórias, palestras sobre a preservação do livro entre outras tantas. São cinco dias úteis por semana e, portanto, 
cinco diferentes comunidades, uma visitada a cada dia da semana, e cada uma com um diferente perfil informacional.

Estudos de uso, realizados sistematicamente e diariamente, a partir da análise dos empréstimos e solicitações feitos, permitem aos funcionários, bibliotecária e bolsistas do Programa inferir o perfil informacional de cada comunidade. Desse modo pode-se afirmar, por exemplo, que no bairro Ipiranga, quanto à tipologia dos materiais emprestados, em primeiro lugar está a literatura estrangeira, com grande procura pelos best sellers, muitas vezes com a procura por títulos recentes. No segundo lugar em empréstimos estão as revistas para adultos. Já no Bairro da Lagoa a maior concentração de empréstimos é de literatura infantil e gibis, mas há grande diversidade de interesses, com muita procura também por literatura estrangeira, filosofia, auto-ajuda, psicologia e religião.

Esses estudos de usos permitem, a cada visita em uma comunidade, adequar o acervo itinerante ao perfil de procura da comunidade. Portanto, antes de se sair para o Bairro da Lagoa, por exemplo, sempre se acrescentam títulos infantis e gibis, que são levados em menor número na véspera, ao bairro Ipiranga. É a partir desses estudos que, também, se implementa a política de seleção para atualização da coleção. Mas esses estudos não são suficientes para a compreensão individual de cada usuário - por mais que a comunidade tenha uma identidade grupal, os indivíduos apresentam necessidades próprias que, nem sempre, se refletem no perfil do grupo.

Para ilustrar essa situação, relata-se aqui um fato ocorrido no bairro da Lagoa, em 2010: em frente ao local em que o ônibus pára semanalmente foi colocado, pela comunidade, um sofá velho. Ali, a cada semana, tão logo o carro-biblioteca se aproxima, os funcionários e bolsistas conseguem avistar, sentados no banco, dois rapazes. Assim que o ônibus pára, eles entram - e o cheiro de bebida alcoólica logo invade o veículo. Durante sua breve visita, discutem os títulos que estão devolvendo e solicitam novos. Os bolsistas (alunos de biblioteconomia que atuam no carro-biblioteca) olham com desconfiança - se já foi estranho ver os dois, na semana anterior, pegar Sartre ou Nietzsche, mais estranho ainda é vê-los discutindo os textos dos autores, comprovando que realmente foram lidos! A primeira impressão que tiveram desses usuários especiais foi de repulsa: a aparência maltrapilha, o odor da bebida, levava à impressão de não pertencimento. O que explicava o interesse literário desses rapazes? Como atendê-los e continuar mantendo seu interesse? Estava aí colocada a função de mediação e a necessidade do "micro estudo" desses usuários. Os bolsistas do programa foram orientados a buscar 
compreender, através da realização de entrevistas com esses usuários e seus familiares, o trinômio "situação-lacuna-auxiliadores" que explicasse o interesse desses usuários pela literatura por eles escolhida. Como resultado dessas entrevistas

Estudo de usuários também foi sugerido nas comunidades dos bairros São Benedito e Frimisa. Uma bolsista decidiu efetuar, nesses dois bairros, um projeto de ação cultural, a que denominou "Contar e Recontar" (MACHADO; SIRIHAL DUARTE, 2011). A ideia central era, através de rodas de contação de histórias, incentivar a leitura e o empréstimo, bem como promover a expressão dos usuários, através da recontação das histórias por eles lidas e do relacionamento dessas histórias com suas experiências e vivências cotidianas. O projeto, a princípio único para as duas comunidades, após o estudo de usuários e a experimentação prática, teve de ser moldado às características inerentes a cada grupo - o que, aliás, está em plena consonância com a definição de ação cultural, uma ação que parte de um planejamento prévio, mas que se desenvolve conforme proposto pelos sujeitos da ação. Coelho Neto (1989) diferencia ação cultural de animação cultural demonstrando que a riqueza da ação cultural está no fato de não propor um projeto pronto, estruturado, com princípio, meio e fim previamente previstos, mas permitir que os atores, sujeitos da ação cultural, construam esse projeto à medida em que ele vai acontecendo. A aplicação do projeto em comunidades distintas foi de fundamental importância para entender os processos de formação de leitores nos diferentes contextos, as influências da leitura sobre os leitores conforme seus espaços de convivências. Os membros de cada comunidade são passíveis de mudanças e podem ser incentivados, entretanto, cada grupo apresenta seus níveis de motivação diferentes e as estratégias para atraí-los também precisam ser diferentes.

Os estudos de usuários propostos nestas duas situações (a mediação de leitura no Bairro da Lagoa e a ação cultural nos bairros Frimisa e São Benedito) se classificam como estudos de necessidades e usos, na concepção de Ribeiro (2009). Também estudos de satisfação são inúmeras vezes propostos no carro-biblioteca. O mais recente, realizado em 2010, avaliou a satisfação dos usuários com um serviço de informação particular oferecido pelo Programa: o Boletim Bairro a Bairro.

O boletim foi proposto em 1997, por iniciativa de uma aluna do Curso de Graduação em Biblioteconomia que, sendo moradora de um dos bairros então atendidos pelo carro-biblioteca, decidiu desenvolver um projeto que contemplasse uma publicação de caráter comunitário. Em sua concepção original, o projeto caracterizou-se pela publicação de informações utilitárias e de 
fácil leitura, visando à comunicação de assuntos do cotidiano das comunidades. Em seu formato atual, o boletim é estruturado em oito páginas, contendo um total de seis seções (as duas primeiras páginas são reservadas à capa e ao editorial e as páginas seguintes às seções): uma matéria principal que tem como tema algum fato importante para a população; uma receita e uma indicação de leitura (preferencialmente, sugeridas por usuários do carro-biblioteca); uma matéria sobre saúde, comportamento e meio ambiente; outra sobre algum serviço oferecido pela UFMG aberto ao público externo e, finalmente, uma matéria sobre cada comunidade visitada, que funciona em sistema de rodízio, de modo que em cada número haja uma matéria sobre uma ou duas das cinco comunidades.

Como método de coleta de dados adotou-se o questionário, aplicado entre 70 leitores do boletim. O questionário foi aplicado pessoalmente por uma bolsista do Projeto Boletim Bairro a Bairro, aproveitando o momento de distribuição do Boletim nas comunidades. Cada usuário que recebia seu exemplar do Boletim era convidado a participar da pesquisa.

Os resultados obtidos da análise, apresentados no XXIV CBBD - Congresso Brasileiro de Biblioteconomia e Documentação (SIRIHAL DUARTE, FARIA e EVANGELISTA, 2011), confirmaram alguns pressupostos (como a grande importância atribuída pelos usuários às seções de Receita e de Dica de Leitura), mas chamaram a atenção para alguns pontos inesperados, apontando para a necessidade de se estreitar os laços entre a UFMG e as comunidades visitadas pelo carro-biblioteca e de se promover uma maior participação dos integrantes dessas comunidades na elaboração do boletim, a fim de que ele efetivamente se constitua num instrumento para "dar voz" aos leitores.

O carro-biblioteca se configura em biblioteca comunitária itinerante e, como tal, é lugar profícuo para a realização de atividades de mediação as mais variadas, em que se deve sempre buscar o atendimento às necessidades informacionais de seus usuários. O perfil do profissional esperado para atuar nesse espaço é o perfil do mediador, daquele que focaliza suas ações todas em função do atendimento das necessidades informacionais de seu usuário - sejam essas necessidades de pesquisa, de informações utilitárias, ou literárias, para fruição e lazer. 


\section{Considerações finais}

Com a mudança do paradigma custodial para o pós-custodial, a mediação (implícita ou explícita) se torna primordial nas instituições como bibliotecas, arquivos e museus. O novo paradigma que se instaura, com um volume cada vez maior de informações circulantes em novo suporte - o suporte virtual, das redes, da Internet, da informação eletrônica - e com uma autonomia cada vez maior do usuário nos processos de busca conduz à reflexão do papel desses profissionais num futuro próximo.

Hoje um estudante prefere, em grande parte das vezes, utilizar o "amigo Google" para fazer suas pesquisas do que fazer uma busca em uma biblioteca. O Google não lhe pede que manipule catálogos ou índices para localizar aquilo de que precisa, não exige o uso de terminologias adequadas, basta que ele informe uma sequência de palavras que representem sua necessidade informacional. Não é necessário mais o mediador! Mas qual é a qualidade das informações obtidas mediante esse tipo de busca?

Em pesquisa realizada em 2006 e publicada em 2008, Furnival e Abe investigam o comportamento informacional de usuários de salas de acesso gratuito à Internet e concluem sua pesquisa questionando ao usuário a quem ele atribui o sucesso ou insucesso de suas pesquisas na Internet. 34 respostas atribuem à ferramenta de busca, 27 à Internet e apenas 12 à forma como são formuladas as expressões de busca (FURNIVAL; ABE, 2008, p. 170). O usuário parece acreditar que a Internet é um oráculo responsável por todo o repertório de informações do mundo, e capaz de fazer o papel do mediador, como num passe de mágica. A Internet (ou a máquina de busca) deve possuir uma "bola de cristal", de modo que com que pouquíssimas palavras que definem uma expressão de busca (as autoras também investigaram a composição das expressões de busca por esses usuários e observaram que apenas 5\% deles utilizam, por exemplo, conectores lógicos de modo correto em suas expressões de busca) ela seja capaz de retornar exatamente aquilo de que o indivíduo necessita. O usuário não só possui pouquíssima competência informacional para formular boas expressões de busca, como não tem sequer a percepção de que sua formulação interfere na qualidade do resultado obtido.

Portanto, conclui-se que o trabalho dos mediadores de informação pode estar mudando de suporte, mas a função de mediação permanece cada vez mais necessária e deve ser cada vez mais importante na formação do profissional. 


\section{Referências}

ALMEIDA JÚNIOR, Oswaldo Francisco de. Mediação da informação e múltiplas linguagens. Tendências da Pesquisa Brasileira em Ciência da Informação, Brasília, v. 2, n.1, p.89103, jan./dez. 2009.

COELHO NETO, José Teixeira. O que é ação cultural. São Paulo: Brasiliense, 1989.

DAVALLON, Jean. A mediação: a comunicação em processo? Prisma.com, n. 4, 2007. Disponível em http://revistas.ua.pt/index.php/prismacom/article/viewFile/645/pdf. Acesso em: 29 maio 2012.

DERVIN, Brenda; NILAN, Michael. Information needs and uses. In: WILLIAMS, Martha E. (ed). Annual Review of Information Science and Technology, v. 21, Chicago, IL: Knowledge Industry Publications, 1986, p. 03-33.

DIAS, Maria Matilde Kronka; PIRES, Daniela. Usos e usuários da informação. São Carlos: EdUFSCar, 2004. 48 p.

FIGUEIREDO, Nice Menezes de. Estudos de uso e usuários da informação. Brasília: IBICT, 1994. $154 \mathrm{p}$.

FURNIVAL, Ariadne C. M.; ABE, Veridiana. Comportamento de busca na Internet: um estudo exploratório em salas comunitárias. Encontros Bibli: Revista Eletrônica de Biblioteconomia e Ciência da Informação, Florianópolis, n. 25, 1º sem. 2008.

GAMA, Fernando Alves; FERNEDA, Edberto. A mediação da informação nos arquivos permanentes: serviços de referência arquivística no ambiente digital. Informação \& Informação, Londrina, v. 15, n.2, p. 147-168, jul./dez. 2010.

GROGAN, D. J. A prática do serviço de referência. Brasília: Briquet de Lemos, 2001.

JARDIM, José Maria e FONSECA, Maria Odila. Estudos de usuários em arquivos: em busca de um estado da arte. Datagramazero, v. 5, n. 5, artigo 04, out./2004. Disponível em: <http://dgz.org.br/out04/Art_04.htm>. Acesso em: 29 maio 2012.

MACHADO, Pamela Bastos; SIRIHAL DUARTE, Adriana Bogliolo. Contar e Recontar Histórias: a contação de histórias como instrumento de ação cultural. In: CONGRESSO BRASILEIRO DE BIBLIOTECONOMIA, DOCUMENTAÇÃO E CIÊNCIA DA INFORMAÇÃO, 24., 2011, Maceió. Anais... Maceió: FEBAB, 2011. Disponível em: <http://febab.org.br/congressos/index.php/cbbd/xxiv/paper/view/178/465 >. Acesso em: 29 maio 2012.

NASCIMENTO, Maria de Jesus. Usuário da informação como produção científica e disciplina curricular: origem dos estudos e o ensino no Brasil. Revista Digital de Biblioteconomia e Ciência da Informação, Campinas, v. 8, n. 2, p. 41-71, jan./jun. 2011. Disponível em <www.brapci.ufpr.br/download.php?dd0=15585 > Acesso em: 29 maio 2012.

NOVELLI, Valéria A. M., HOFFMANN, Wanda A. M. e GRACIOSO, Luciana de Souza. Reflexões sobre a mediação da informação na perspectiva dos usuários. Biblionline, João 
Pessoa, v. 7, n. 1, p.3-10, 2011. Disponível em:

$<$ http://periodicos.ufpb.br/ojs2/index.php/biblio/ article/viewFile/9570/5790 >. Acesso em: 29 maio 2012.

RABELLO, Odília Clark Peres. O conteúdo do campo de conhecimento relativo a usuário de biblioteca. In: Análise do campo de conhecimento relativo a usuário de

biblioteca. 1980. 116 f. Dissertação (Mestrado) - Escola de Biblioteconomia, Universidade Federal de Minas Gerais, 1980. Cap. 4.

RABELLO, Odília Clark Peres. O usuário nos currículos de Biblioteconomia. Revista da Escola de Biblioteconomia UFMG, Belo Horizonte, v. 10, n. 2, p. 179-192, set. 1981. Disponível em: <http://portaldeperiodicos.eci.ufmg.br/reb/> . Acesso em: 29 maio 2012.

RIBEIRO, Fernanda. O papel mediador da ciência da informação na construção da sociedade em rede. 2009, p. 21-38. Disponível em: <http://repositorioaberto.up.pt/bitstream/10216/26612/2/FRibeiropapelmediadorCI000108385.pdf $>$. Acesso em: 29 maio 2012.

SILVA, Armando Malheiro. Mediações e mediadores em Ciência da Informação. Prisma.com, n. 9, 2010. Disponível em: <http://prisma.cetac.up.pt/Prisma.Com_n9Mediacao_e_mediadores_em_Ciencia_da_Informacao.pdf $>$. Acesso em: 29 maio 2012.

SIRIHAL DUARTE, Adriana Bogliolo; FARIA, Raquel Carvalho de; EVANGELISTA, Paola. Avaliação de um serviço de disseminação da informação: o Boletim Bairro a Bairro na concepção dos usuários do Carro-Biblioteca da UFMG. In: CONGRESSO BRASILEIRO DE BIBLIOTECONOMIA, DOCUMENTAÇÃO E CIÊNCIA DA INFORMAÇÃO, 24., 2011, Maceió. Anais... Maceió: FEBAB, 2011. Disponível em: <http://febab.org.br/congressos/index.php/cbbd/xxiv/paper/view/180/516 > . Acesso em: 29 maio 2012.

SMIT, Johanna W. Arquivologia/Biblioteconomia: interfaces das ciências da informação. Informação \& Informação, Londrina, v. 8, n. 2, jul./dez. 2003. Disponível em: <http://www.uel.br/revistas/uel/index.php/informacao/article/view/1713/1464>. Acesso em: 29 maio 2012.

TALJA, Sanna. Constituting "information" and "user" as research objects: a theory of knowledge formations as an alternative to the information man-theory. In: VAKKARI, Perti; SAVOLAINEN, Reijo; DERVIN, Brenda (Eds). Information seeking in context. Londres: Taylor Graham, 1996, p. 67-80.

TARGINO, M. G. Conceito de biblioteca. Brasília: ABDF, 1984.

TERUEL, Aurora González. Los estudios de necesidades y usos de la información: fundamentos y perspectivas actuales. Madri: Trea, 2005.

WILSON, T. D. Human information behavior. Informing Science, v. 3, n. 2, p. 49-54, 2000. 